\title{
Rancang Bangun Purwarupa Penerima Paket APRS Berbasis Raspberry Pi 2 untuk Stasiun Bumi
}

\author{
Agfianto Eko Putra*¹, Unggul Adhi Nugroho ${ }^{2}$, Bakhtiar Alldino Ardi Sumbada ${ }^{3}$, \\ Catur Atmaji ${ }^{4}$ \\ ${ }^{1,3,4}$ Departemen Ilmu Komputer dan Elektronika, FMIPA UGM, Yogyakarta \\ ${ }^{2}$ Program Studi Elektronika dan Instrumentasi, DIKE, FMIPA,UGM, Yogyakarta \\ e-mail : *1 agfi68@gmail.com, ${ }^{2}$ unggul.adn@gmail.com, \\ b.alldino.as@ugm.ac.id, ${ }^{3}$ catur atmaji@ugm.ac.id
}

\begin{abstract}
Abstrak
Telah dirancang-bangun penerima paket APRS berbasis Raspberry Pi 2 untuk stasiun bumi. Tuner TV digunakan sebagai penerima sinyal, alat penerima diakses melalui laptop secara nirkabel. Antena Yagi dengan sebuah pengendali digunakan agar dapat secara otomatis mengarahkan ke satelit. Ujicoba dilakukan dengan menerima paket APRS yang dipancarkan digipeater satelit International Space Station (ISS) dan satelit LAPAN-A2. Hasil penelitian menunjukkan bahwa alat ini mampu mendapatkan paket APRS satelit ISS dengan jumlah 6 paket dari 10 paket yang dipancarkan. Paket yang diterima memiliki rata-rata amplitudo pada frekuensi $1.200 \mathrm{~Hz}$ dan $2.200 \mathrm{~Hz}$ yang bernilai jauh lebih kecil dibandingkan amplitudo audio keseluruhan. Hal ini menunjukkan bahwa terdapat derau yang tinggi pada sinyal. Sedangkan paket APRS dari satelit LAPAN-A2 belum berhasil diperoleh.
\end{abstract}

Kata kunci-Radio Amatir, Dire Wolf, ISS, LAPAN-A2, rtl_fm, RTL-SDR

\begin{abstract}
The design of Raspberry Pi 2-based APRS packets for UGM earth stations has been designed. A TV tuner is used as a signal receiver, the receiver is accessed via a laptop wirelessly. A Yagi Antenna with a controller is used to automatically point to the satellite. The test was carried out by receiving the APRS package emitted by the International Space Station (ISS) satellite and the LAPAN-A2 satellite. The results showed that this tool was able to get the ISS satellite APRS package with a total of 6 packages out of 10 packets emitted. The package received has an average amplitude of $1,200 \mathrm{~Hz}$ and 2,200 $\mathrm{Hz}$ which is much smaller than the overall audio amplitude. This indicates that there is high noise in the signal. While the APRS package from the LAPAN-A2 satellite has not been successfully obtained.
\end{abstract}

Keywords - Amateur Radio, Dire Wolf, ISS, LAPAN-A2, rtl_fm, RTL-SDR

\section{PENDAHULUAN}

Satelit yang memiliki digipeater akan menunjang kinerja radio amatir dengan cara menerima sinyal (informasi) dari area terrestrial yang dapat berupa paket APRS (Automatic Packet Reporting System). Kemudian dipancarkan kembali ke area terrestrial sehingga radio amatir di area lain dapat mengetahui isi informasinya. Radio amatir menggunakan perangkat transceiver dengan dukungan APRS untuk saling bertukar informasi dalam bentuk teks, namun, perangkat dengan dukungan APRS memiliki harga yang relatif mahal.

Sruthi dkk. melakukan penelitian mengenai rancangan pemancar-penerima (transceiver) untuk SDR (Software Define Radios) menggunakan RTL-SDR. Pemancar-penerima berbasis Personal Computer (PC). Pemancar menggunakan mixer agar dapat mengakses seluruh pita 
frekuensi DC (Direct Current) hingga 1.700 MHz. Sedangkan penerima, digunakan RTL-SDR yang memiliki jangkauan frekuensi $64 \mathrm{MHz}$ hingga 1,7 GHz. Metode yang diusulkan tersebut menggunakan RF mixer dan RTL-SDR yang lebih cocok untuk transmisi sinyal dan penerimaan karena biayanya yang relatif rendah [1].

Sistem yang dibuat oleh Danymol dkk., yakni RTL-SDR dan Raspberry Pi sebagai penerima sinyal FM, ditransfer ke remote PC. RTL-SDR yang digunakan memiliki tuner chip Elonics E4000. Sedangkan proses pemantauan dilakukan pada lokasi yang berbeda secara jarak jauh menggunakan WiFi untuk mengirim data SDR, sehingga sistem komunikasi secara realtime dapat dilakukan. Sinyal FM pada frekuensi 98,3 MHz yang diterima oleh RTL-SDR dikirim menggunakan TCP server melalui LAN ke remote PC. Spektrum sinyal FM diwujudkan menggunakan perangkat lunak SDR Sharp yang dipasang di remote PC [2].

Hadjaveric dkk. melakukan implementasi Client-Server untuk APRS-IS (APRS Internet Service) menggunakan Raspberry Pi. Sistem yang dirancang memiliki komponen utama Raspberry Pi, RTL-SDR, smartphone android dan sebuah pemancar-penerima. Perangkat lunak yang digunakan adalah Raspbian Debian (Wheezy), pymultimonaprs dan aprsdroid. Raspberry Pi terhubung ke router atau firewall melalui kabel UTP atau WiFi untuk beralih ke perangkat komunikasi lainnya. Hasil dapat diamati pada laman http://aprs.fi, yaitu unit klien yang dapat mengirim perubahan lokasi GPS ke unit server melalui RF 144,800 MHz dengan radius 200 meter dengan hanya menggunakan antena bawaan [3].

Berbeda dengan penelitian sebelumnya, penelitian ini bertujuan merancang-bangun sebuah penerima paket APRS berbasis Raspberry Pi 2 (dengan perangkat lunak rtl_fm dan Dire Wolf), RTL-SDR dengan memanfaatkan Antena Yagi yang dilengkapi dengan sebuah pengendali agar dapat secara otomatis mengarah ke satelit.

\section{METODE PENELITIAN}

\subsection{APRS}

APRS atau Automatic Packet Reporting System, yang dirancang oleh Bob Bruninga (WB4APR) dan diperkenalkan di TAPR/ARRL (Tucson Amateur Packet Radio/American Radio Relay League) Digital Communications Conference tahun 1992, adalah sebuah protokol paket komunikasi untuk menyebarluaskan data kepada semua orang di jaringan secara real-time. APRS merupakan kombinasi paket radio dengan jaringan satelit Global Positioning System (GPS), yang memungkinkan radio amatir untuk secara otomatis menampilkan posisi stasiun radio dan benda-benda lain pada peta di komputer atau laptop.

\subsection{Paket Radio AFSK 1.200}

APRS menggunakan teknik modulasi AFSK (Audio Frequency Shift Keying), dimana data digital diwakili oleh perubahan frekuensi (pitch) nada audio. Biasanya, audio yang ditransmisikan bergantian antara dua nada: "tanda", mewakili satu biner; yang lain, "ruang", mewakili nol biner. AFSK memiliki keuntungan yaitu mampu bekerja melalui jalur audio biasa, yang membuatnya cocok untuk digunakan pada radio yang dirancang untuk suara [5]. Bit order yang digunakan adalah LSB. Data link layer yang digunakan adalah AX.25.

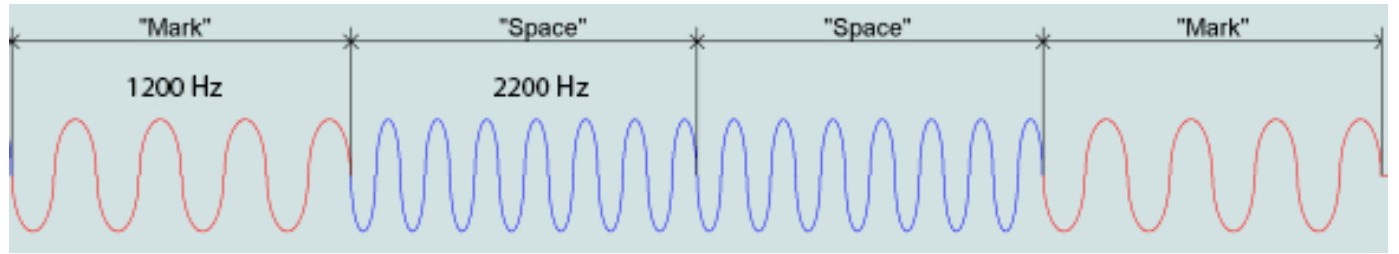

Gambar 1. Urutan biner 1001 dengan modulasi FSK [6]

IJEIS Vol. 9, No. 1, April 2019: $75-86$ 
Gambar 1 menunjukkan urutan biner yang dimodulasi dengan FSK, frekuensi sinyal yang dipancarkan digeser dengan perubahan fasa minimal seperti tampak pada amplitudo modulasi sinyal tidak berubah. Karena hanya menggunakan dua frekuensi harmonik, spektrum dari sinyal yang ditransmisikan sempit (tidak lebih dari $3 \mathrm{kHz}$ ), yang memungkinkan sinyal untuk lewat dengan bebas melalui jalur dial-up komunikasi jarak jauh.

\subsection{Perangkat Lunak Tracking Satelit}

Perangkat lunak tracking satelit, Orbitron, adalah perangkat lunak yang digunakan untuk memprediksi posisi satelit. Data masukan yang digunakan untuk prediksi posisi satelit yaitu data Two Line Element (TLE) dan lokasi pengamat. Luarannya digunakan sebagai masukan ke pengarah atau rotator antena, berupa posisi satelit yang telah dikonversi ke dalam azimuth dan elevasi untuk pengamat (pengarah antena).

\subsection{Perangkat Lunak APRSDroid}

APRSdroid adalah sebuah aplikasi Android untuk operator radio amatir[8]. Perangkat lunak ini digunakan untuk pelaporan posisi pada APRS, perangkat lunak ini mampu menampilkan stasiun radio amatir di dekatnya serta untuk pertukaran data pesan APRS.

\subsection{Perangkat Keras Rotator Antena}

Rotator antena, sebagaimana ditunjukkan pada Gambar 2, digunakan untuk menggerakkan Antena Yagi dengan besar penguatan kurang lebih $8 \mathrm{~dB}$. Rotator antena dikendalikan menggunakan mikrokontroler untuk mengarahkan antena ke posisi satelit secara realtime sesuai data masukan, yang berupa data TLE dari perangkat lunak tracking satelit.

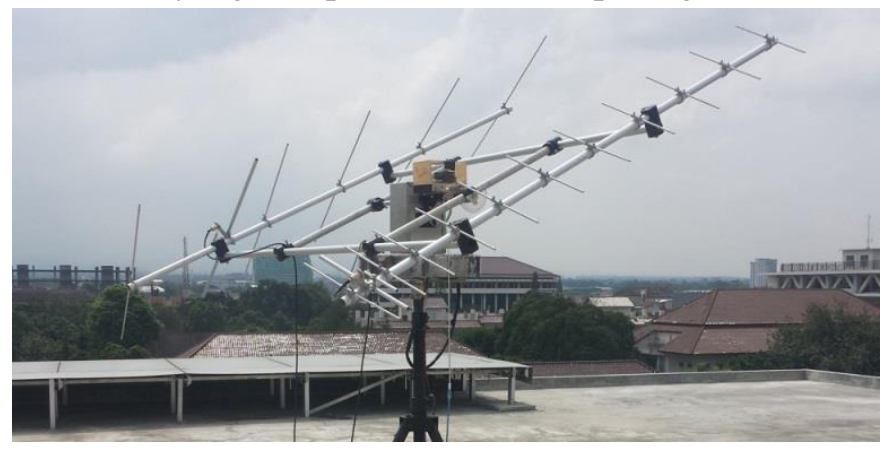

Gambar 2. Perangkat keras rotator antena yang digunakan

\subsection{Rancangan Perangkat Keras}

Rancangan perangkat keras utama, sebagaimana ditunjukkan pada Gambar 3, terdiri atas Raspberry Pi 2 dan RTL-SDR. Raspberry Pi 2 dihubungkan dengan RTL-SDR melalui USB. Tuner yang digunakan adalah Rafael R820T2.

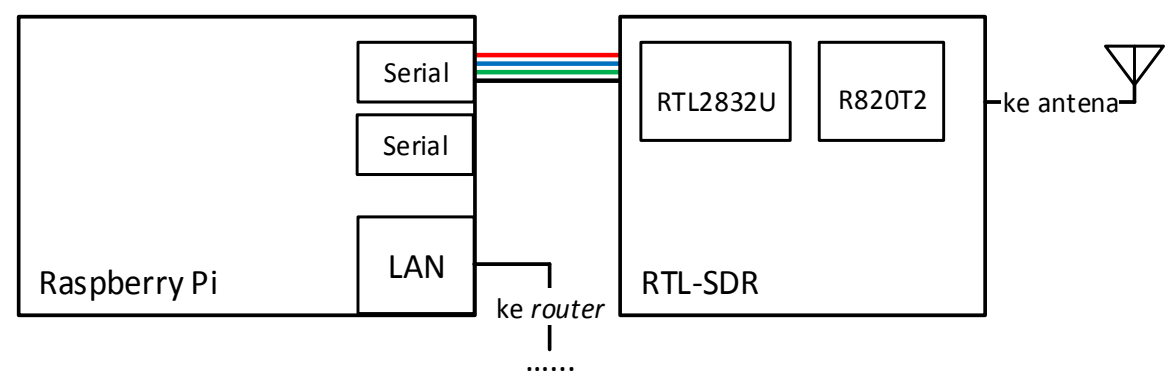

Gambar 3. Rancangan perangkat keras utama 


\subsubsection{Modifikasi RTL-SDR}

RTL-SDR dapat secara langsung digunakan sebagai penerima frekuensi tinggi, akan tetapi penggunaan dalam jangka waktu lama dapat menyebabkan pergeseran offset pada frekuensi [9]. TCXO (Temperature Compensated Crystal Oscillator) digunakan agar offset frekuensi lebih stabil.

Gambar 4 (kiri) merupakan skematik RTL-SDR yang menggunakan TCXO (tanda kotak). Gambar 4 (kanan) adalah skematik ADC 7-bit Realtek RTL2832U, regulator daya 3,3V dan 1,2V. Hal yang umum menambahkan kapasitor filter pada VBUS USB [10], karena kabel jumper dapat berfungsi layaknya sebuah antena. Penapis pi ditambahkan setelah luaran regulator daya, digunakan untuk mengurangi riak pada luaran regulator daya.
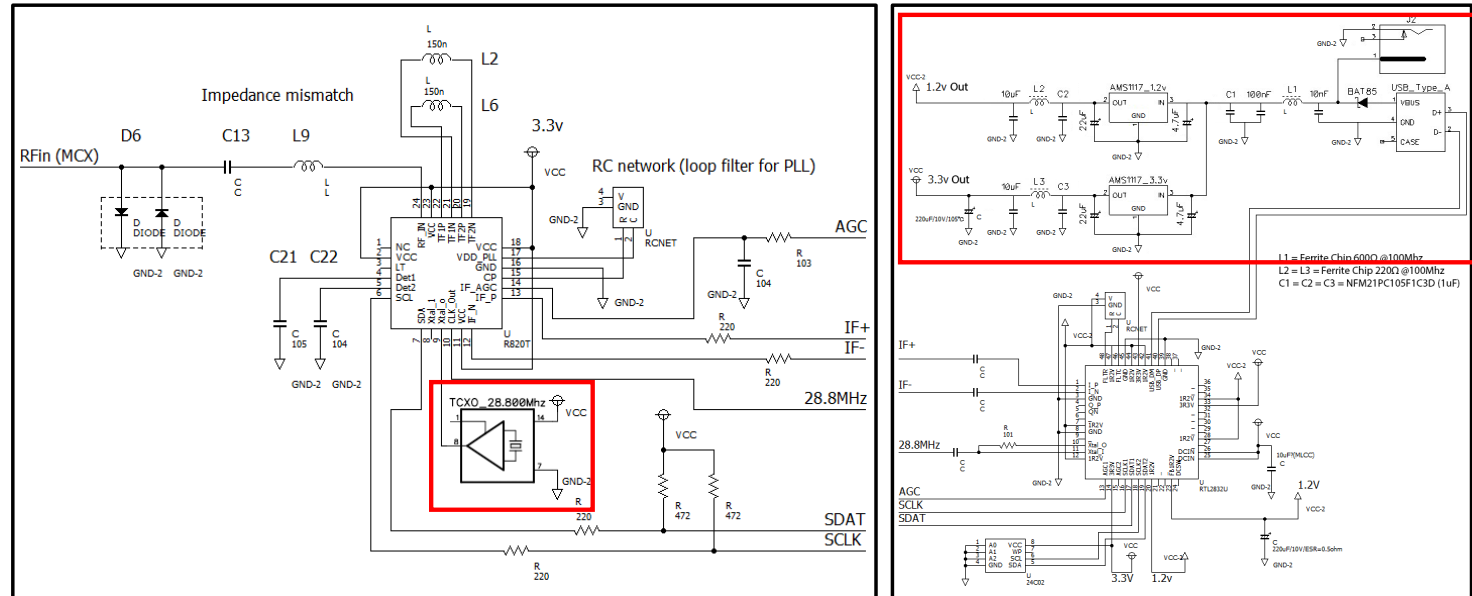

Gambar 4 Skematik pada rangkaian tuner dan TCXO (kiri), skematik pada rangkaian

RTL2832U dan regulator daya (kanan)

\subsection{Penggunaan Perangkat Lunak}

\subsubsection{Perangkat Lunak Pada Raspberry Pi 2}

Perangkat lunak yang digunakan pada Raspberry Pi 2 adalah perangkat lunak pengoperasian RTL-SDR, yaitu rtl_fm dan Dire Wolf. Perintah yang diberikan untuk Raspberry Pi 2 adalah menjalankan rtl_fm kemudian di-pipe dengan perintah Dire Wolf. Diagram proses penerimaan sinyal hingga penampilan paket APRS ditunjukkan pada Gambar 5.

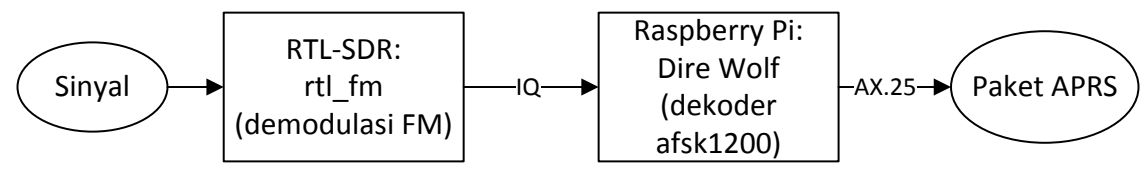

Gambar 5. Diagram proses penerimaan hingga penampilan paket APRS

\subsubsection{Program Demodulator FM}

Program demodulator FM yang digunakan adalah rtl_fm, yang merupakan demodulator FM untuk perangkat penerima berbasis RTL2832 [12]. Source code rtl_fm dapat diunduh di laman https://github.com/keenerd/rtl-sdr/. Pengujian dilakukan pada frekuensi 145,825 MHz dan laju pencuplikan $22.050 \mathrm{~Hz}$. Pengaturan luaran pada program ini adalah standard output (stdout) agar dapat diteruskan oleh perintah pada program selanjutnya yaitu Dire Wolf sebagai dekoder APRS. 


\subsubsection{Program Dekoder APRS}

Program dekoder APRS yang digunakan adalah Dire Wolf (Decoded Information from Radio Emissions for Windows Or Linux Fans), yang merupakan perangkat lunak modem soundcard/TNC (Terminal Node Controller) dan untuk enkode/dekode APRS. Source code-nya dapat diunduh pada laman https://github.com/wb2osz/direwolf.

\section{HASIL DAN PEMBAHASAN}

\subsection{Implementasi Perangkat Keras}

\subsubsection{TCXO dan regulator daya pada RTL-SDR}

Gambar 6 menunjukkan papan rangkaian RTL-SDR, regulator daya $1,2 \mathrm{~V}$ dan 3,3V, filter untuk regulator daya, TCXO $28,8 \mathrm{Mhz}$ dan jack mini DC untuk daya ekstra apabila daya yang dikeluarkan Raspberry Pi 2 tidak mencukupi. Dioda (Schottky BAT85) ditambahkan pada bagian antara VBUS USB dengan Vout pada jack mini DC. Dioda ini berfungsi untuk mencegah arus mengalir dari Vout jack ke VBUS USB sehingga Raspberry Pi 2 tetap aman.

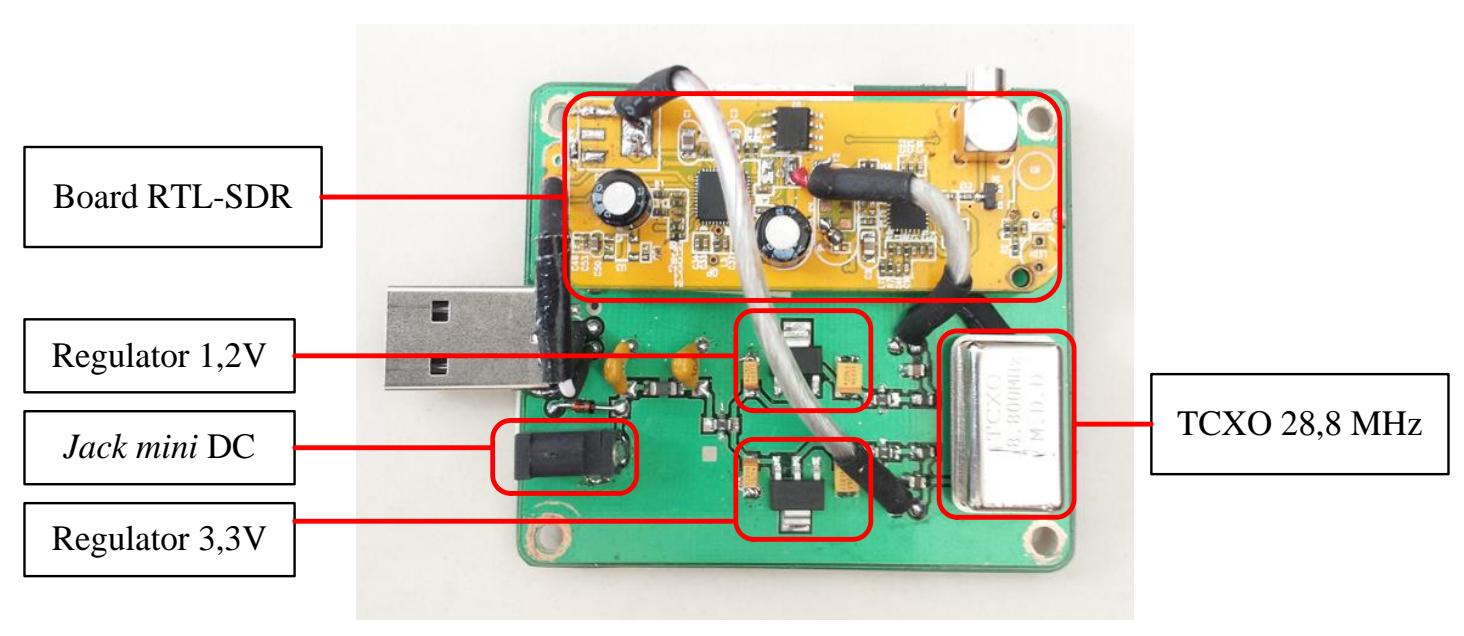

Gambar 6 TCXO dan regulator daya

\subsubsection{Perangkat Keras Utama}

Gambar 7 menunjukkan rangkaian perangkat keras utama. Raspberry Pi 2 dihubungkan dengan PC/laptop melalui wireless router, juga dihubungkan dengan RTL-SDR melalui USB. Antena Yagi dihubungkan ke RTL-SDR menggantikan antena bawaan. Rangkaian dengan dioda dan terminal block digunakan untuk mendistribusikan daya ke Raspberry Pi 2 dan wireless router. Wireless router pada penerima dikonfigurasi sebagai server. Sedangkan wireless router sebagai client digunakan untuk koneksi ke PC/laptop. 


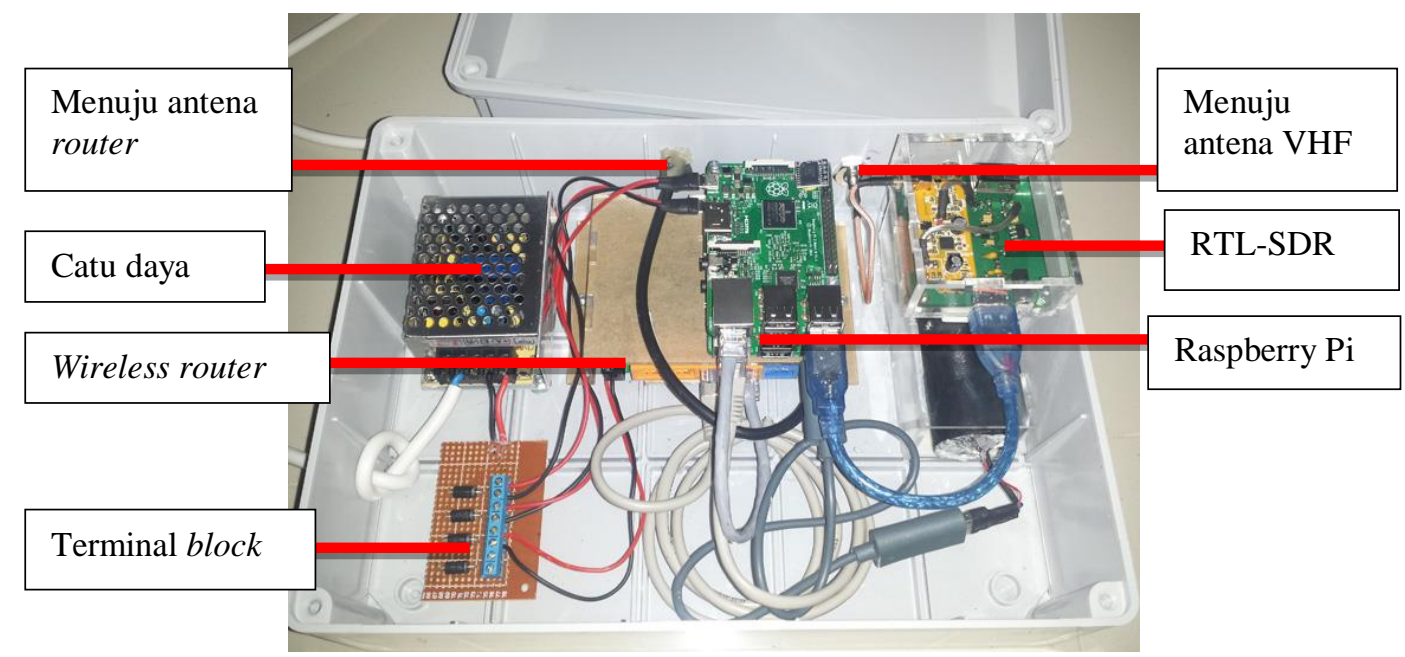

Gambar 7. Perangkat keras utama

\subsection{Implementasi Perangkat Lunak}

\subsubsection{Sesi SSH pada Raspberry Pi}

Sesi SSH ditunjukkan pada Gambar 8, pengaturan alamat ip untuk Raspberry Pi 2 adalah 192.168.0.107, sedangkan laptop beralamatkan 192.168.0.7. Laptop dikonfigurasi sedemikian rupa sehingga koneksi internet laptop dapat dibagi ke Raspberry Pi agar dapat dilakukan pembaruan dan pemasangan perangkat lunak.

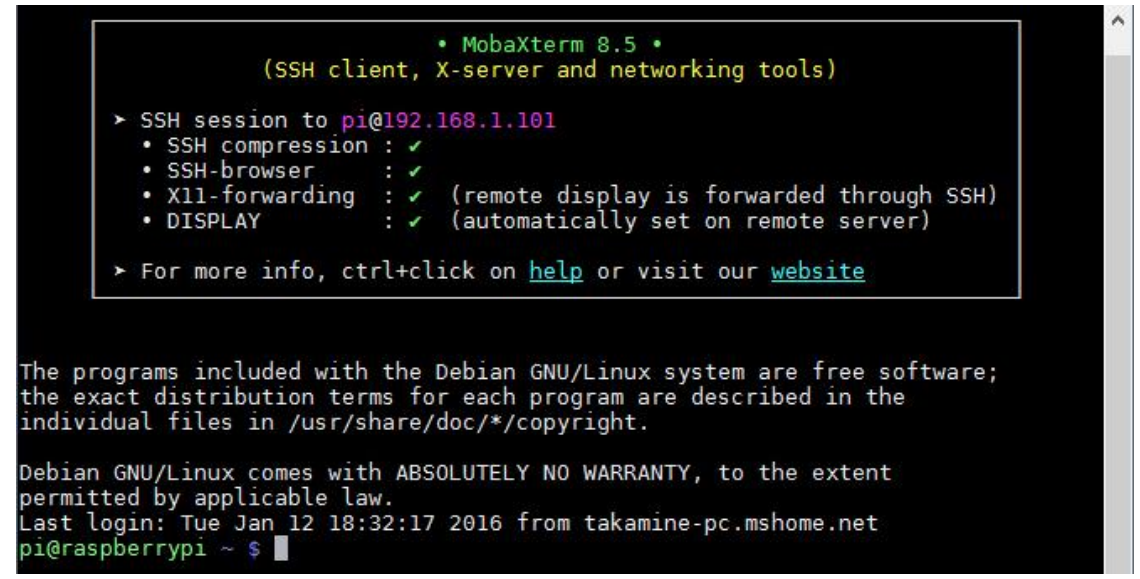

Gambar 8 Sesi SSH pada Raspberry Pi dengan MobaXterm

\subsubsection{Program rtl_fm}

Gambar 9 merupakan tampilan pilihan perintah pada rtl_fm yang menunjukkan pilihan beberapa perintah yang tersedia. Beberapa pilihan yang tersedia yaitu pengaturan frekuensi, jenis modulasi, pengaturan sample rate (nilai default $24 \mathrm{kHz}$,) indeks perangkat (default 0 ), dan tuner gain. 


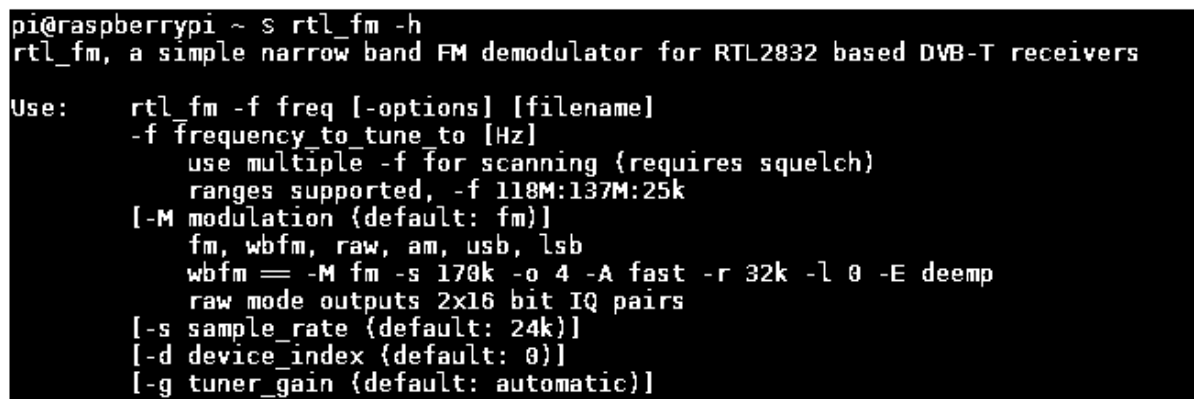

Gambar 9 Pilihan perintah pada program rtl_fm

\subsubsection{Program Dire Wolf}

Gambar 10 menunjukkan tampilan menu bantuan pada Dire Wolf dengan pilihan beberapa perintah yang tersedia. Beberapa pilihan yang tersedia adalah pengaturan nama berkas konfigurasi, lokasi berkas log, sample rate audio, jumlah channel, bit-depth audio, dan data rate (nilai default adalah 1.200).

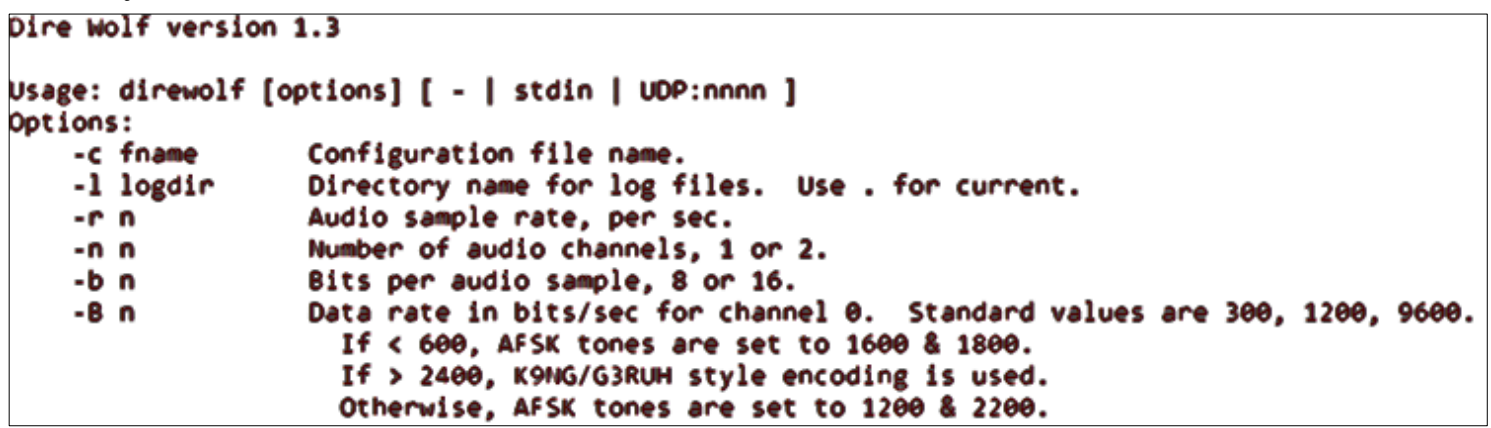

Gambar 10 Pilihan perintah pada program Dire Wolf

\subsubsection{Demodulasi dan dekode}

Proses demodulasi dan dekode pada Raspberry Pi dilakukan menggunakan perintah yang ditunjukkan pada Gambar 11. Perintah "rtl_fm" digunakan untuk melakukan demodulasi sinyal frekuensi tinggi. "-f 145.825M" untuk melakukan demodulasi pada frequensi 145,825 Mhz. "-s 22050" sample rate diatur ke $22.050 \mathrm{~Hz}$. Tanda “-" digunakan untuk memasukkan data ke stdin. "|" untuk melakukan pipe perintah selanjutnya. Pada perintah Dire Wolf terdapat "-n 1" yaitu channel diatur ke 1, “-r 22050" sample rate diatur ke $22.050 \mathrm{~Hz}$. "-D 1" membagi sample audio menjadi 1. "-a 300" menampilkan statistik audio setiap 300 detik. "-1 /home/pi/Documents/" menyimpan log data ke lokasi /home/pi/Documents/.

rtl_fm -f 145.825M -s 22050 - | direwolf -n 1 -r 22050 -D 1 -a 300 -1 /home/pi/Documents/ -

Gambar 11 Perintah untuk melakukan demodulasi dan dekode

\subsection{Pengujian Sistem}

\subsubsection{Pengujian Kestabilan Frekuensi}

Perangkat lunak yang digunakan untuk pengujian adalah SDRSharp, Gambar 12 (kiri) menunjukkan pergeseran offset frekuensi pada 101,700 Mhz ke 101,695 Mhz atau sekitar $5 \mathrm{kHz}$ setelah 10 menit penggunaan pada RTL-SDR bawaan. Kemudian setelah digunakan TCXO, seperti ditunjukkan pada Gambar 12 (kanan), performa RTL-SDR pada penerimaan radio FM, setelah lebih dari 10 menit dinyalakan, tampak offset frekuensinya lebih stabil pada 101,700 MHz. 

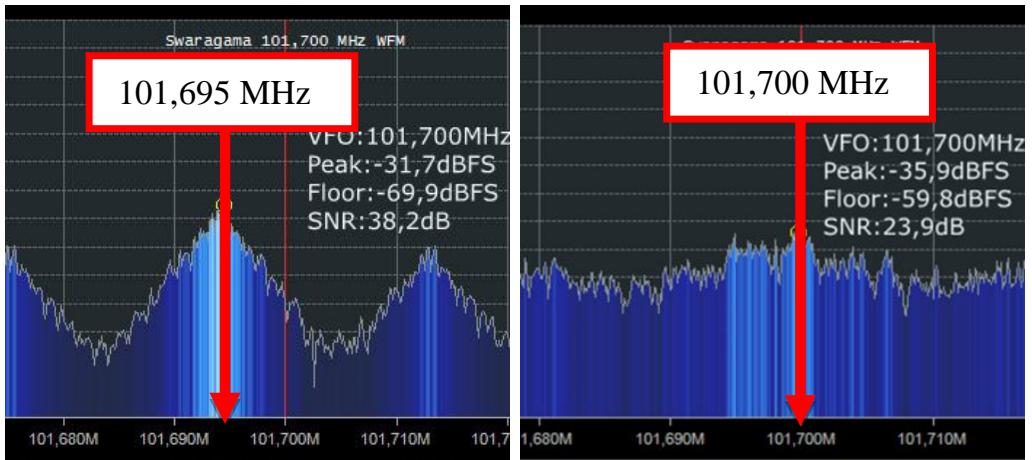

Gambar 12 Pergeseran offset frekuensi (kiri) dan offset frekuensi lebih stabil (kanan)

Kestabilan offset frekuensi akan sangat berpengaruh terhadap penerimaan sinyal dari satelit. Ketika terjadi pergeseran frekuensi akibat efek doppler, total pergeseran yang lebih besar dapat terjadi bila offset frekuensi pada RTL-SDR juga bergeser. Misalnya, dari satelit, frekuensi bergeser $-4 \mathrm{KHz}$ akibat efek doppler dan dari RTL-SDR bergeser $-5 \mathrm{KHz}$. Maka total pergeseran adalah $-9 \mathrm{KHz}$, dari frekuensi 145,825 MHz menjadi 145,816 MHz. Hal ini dapat menyebabkan paket APRS tidak dapat didekode oleh dekoder.

\subsubsection{Pengujian pada Satelit ISS}

Pemancaran pada digipeater APRS satelit dilakukan menggunakan radio UHF/VHF dengan daya 10 Watt dan antena yagi. Pemancaran dilakukan menggunakan aplikasi APRSDroid pada smartphone yang dihubungkan ke radio. Posisi pemancaran paket adalah tetap. Volume suara untuk APRSDroid diatur ke $100 \%$. Antena yagi digunakan pada radio. Radio diatur ke frekuensi 145,825 Mhz dan penerima diatur ke frekuensi yang sama pula. Pemancaran beacon akan dilakukan 1 menit sekali, karena pada APRSDroid dibatasi minimal 1 menit setiap transmisi beacon. Potongan paket yang diterima dari digipeater ISS ditunjukkan pada Gambar 13.

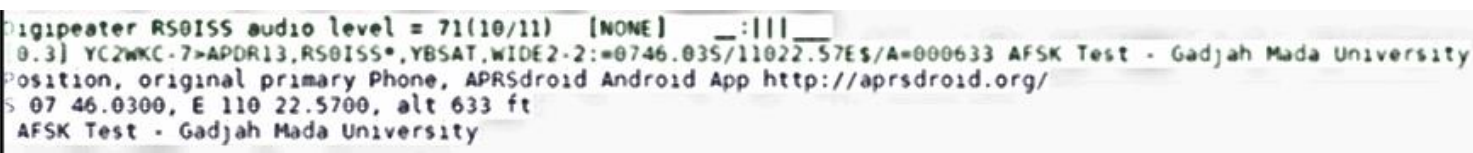

Gambar 13 Potongan paket yang diterima dari digipeater ISS

Paket yang dipancarkan berupa beacon lokasi pemancaran dan dengan isi komentar "AFSK Test - Gadjah Mada University". Callsign pengguna adalah YC2WKC-7. Path yang digunakan adalah RS0ISS, YBSAT dan WIDE2-2. "0746.03S/11022.57E $\$ / A=000633 "$ adalah posisi radio pemancar. Paket yang diterima memiliki data payload yang sama dengan data pemancar. Perbedaannya adalah pada path, yaitu tanda asterisk (*) pada RSOISS* yang menandakan bahwa paket APRS telah berhasil dilakukan digipeating oleh ISS. Dire Wolf menampilkan amplitudo audio secara presentase, pada paket pertama, 71 adalah volume audio, yaitu nilai amplitudo puncak ke puncak pada audio. Sedangkan angka 10/11 adalah nilai amplitudo setengah puncak ke puncak. 10 adalah amplitudo untuk frekuensi $1.200 \mathrm{~Hz}$ (untuk mark atau 1), sedangkan 11 adalah amplitudo untuk frekuensi $2.200 \mathrm{~Hz}$ (untuk space atau 0). Rasio amplitudo dalam desibel didapatkan menggunakan persamaan (1).

$$
G_{d B}=20 \log _{10}\left(A_{2} / A_{1}\right)
$$

Satelit ISS melintas dalam jangkauan penerima selama kurang lebih 10 menit. Waktu ini disebut dengan waktu Acquisition of Signal (AOS), pada 10 kali pemancaran paket beacon, hanya didapatkan 6 paket dari digipeater satelit. Dua paket pada menit awal dan menit akhir tidak diterima oleh penerima. Dua menit awal dan akhir, sudut elevasi antara satelit dan penerima bernilai kecil. Sudut elevasi yang kecil menyebaban sinyal yang dipancarkan dapat 
terhambat oleh permukaan bumi. Gambar 14 menunjukkan grafik amplitudo sinyal yang diterima dari digipeater ISS.

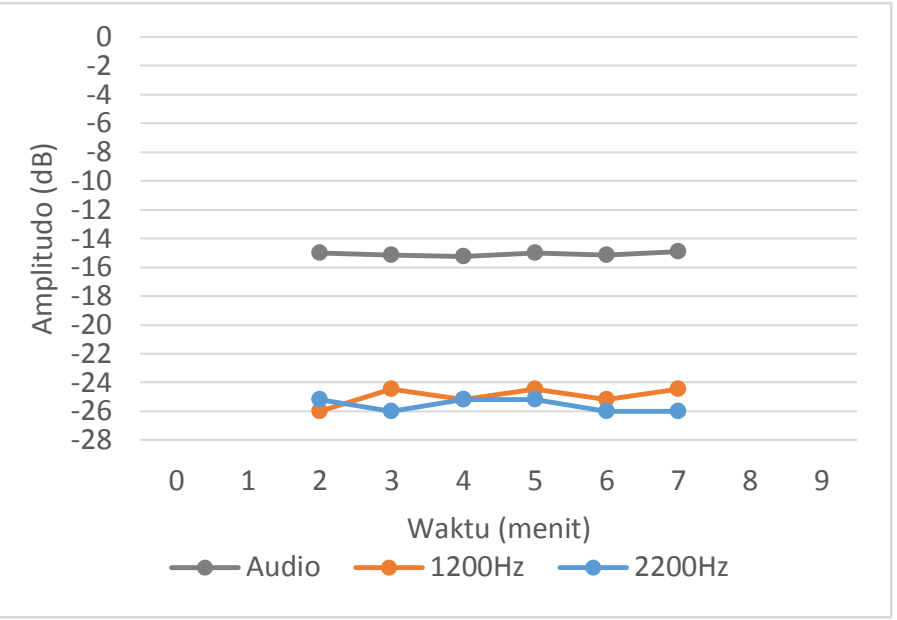

Gambar 14 Grafik amplitudo pada penerimaan paket dari digipeater ISS

Amplitudo audio memiliki nilai rata-rata $-15,08 \mathrm{~dB}$, rata-rata amplitudo pada $1.200 \mathrm{~Hz}$ adalah $-24,95 \mathrm{~dB}$ dan $2.200 \mathrm{~Hz}$ adalah $-25,61 \mathrm{~dB}$. Amplitudo audio keseluruhan memiliki nilai yang lebih besar, hal ini dapat disebabkan oleh interferensi dari lingkungan luar sehingga menyebabkan adanya derau yang tinggi. Selain itu dapat pula disebabkan oleh efek doppler shift, yang menyebabkan pergeseran frekuensi yang diterima dan dipancarkan satelit. Sehingga pada frekuensi $145,825 \mathrm{MHz}$ tidak diperoleh sinyal yang kuat. Nilai rata-rata amplitudo yang diperoleh ditunjukkan pada Tabel 1.

Tabel 1. Nilai rata-rata amplitudo hasil pengujian pada satelit ISS

\begin{tabular}{|l|l|l|l|}
\hline & Audio & $1.200 \mathrm{~Hz}$ & $2.200 \mathrm{~Hz}$ \\
\hline Amplitudo & $-15,08 \mathrm{~dB}$ & $-24,95 \mathrm{~dB}$ & $-25,61 \mathrm{~dB}$ \\
\hline
\end{tabular}

\subsubsection{Pengujian pada satelit LAPAN-A2}

Pengujian penerimaan paket APRS dari digipeater satelit LAPAN-A2 tidak berhasil. Digipeater LAPAN-A2 memiliki daya 5 Watt. Sedangkan daya digipeater APRS pada satelit ISS adalah 20 Watt. Penguatan (gain) pada daya dalam desibel dihitung menggunakan persamaan (2).

$$
\operatorname{Gain}_{d B}=10 \log _{10}\left(P_{2} / P_{1}\right)
$$

Sehingga diketahui penguatan daya pada LAPAN-A2 adalah 6,99 dB, sedangkan pada ISS adalah 13,01 dB. Jadi, penguatan daya pada digipeater satelit LAPAN-A2 lebih kecil 6,01 dB dibandingkan gain daya pada digipeater ISS.

Satelit LAPAN-A2 mengorbit dengan ketinggian kurang lebih $636 \mathrm{~km}$, ketinggian ini lebih jauh dibandingkan dengan satelit ISS yang sejauh kurang lebih $406 \mathrm{~km}$. Jarak yang di tempuh oleh sinyal menuju stasiun bumi menyebabkan sinyal yang diterima menjadi jauh lebih kecil. Hubungan antara jarak dan kerugian sinyal atau free-space path loss (FSPL) ditunjukkan oleh persamaan (3).

$$
F S P L_{d B}=20 \log _{10}(d)+20 \log _{10}(f)+20 \log _{10}\left(\frac{4 \pi}{c}\right)
$$

Frekuensi APRS untuk satelit LAPAN-A2 sama dengan satelit ISS yaitu 145,825 MHz. Sehingga diketahui nilai FSPL (Free Space Path Loss) untuk satelit LAPAN-A2 adalah 131,79 dB sedangkan untuk satelit ISS adalah 127,89 dB. Jadi nilai $F S P L$ untuk satelit LAPAN-A2 lebih besar 3,9 dB dari pada nilai FSPL untuk satelit ISS. Hasil ini menunjukkan bahwa besar jarak berbanding lurus dengan besar kerugian sinyal selama transmisi, semakin besar jarak maka semakin besar kerugian sinyal, menyebabkan semakin kecil sinyal yang diterima oleh 
stasiun bumi. Rata-rata amplitudo frekuensi $1.200 \mathrm{~Hz}$ dan $2.200 \mathrm{~Hz}$ (nada AFSK) pada paket yang didapatkan dari satelit ISS secara berurutan bernilai -24,95 dB dan -25,61 dB, maka pada satelit LAPAN-A2 bernilai lebih kecil. Sehingga nada AFSK tidak dapat dideteksi oleh dekoder dan tidak ada paket yang bisa ditampilkan.

Dengan demikian, pengujian paket data APRS pada satelit LAPAN-A2 tidak berhasil dilakukan karena satelit memiliki penguatan daya yang lebih kecil dan kerugian sinyal yang lebih besar dibanding satelit ISS. Hal ini juga berlaku untuk satelit lainnya, karena sebagian besar satelit memiliki digipeater APRS dengan daya yang lebih kecil dan memiliki orbit dengan ketinggian yang lebih dari satelit ISS, sehingga paket tidak berhasil diperoleh. Selain itu, tidak semua satelit memiliki digipeater APRS yang aktif, sehingga hanya diperoleh paket APRS dari satelit ISS.

\subsubsection{Pengujian pada stasiun cuaca}

Pengujian dilakukan pada stasiun cuaca (weather station) dengan callsign YE2YE-13, yang memiliki jarak sekitar $7 \mathrm{~km}$ dari posisi penerima. Penerima diatur ke frekuensi yang sama. Gambar 15 (kiri) menunjukkan potongan paket yang diterima dari YE2YE-13 dan Gambar 15 (kanan) adalah grafik amplitudo-nya.
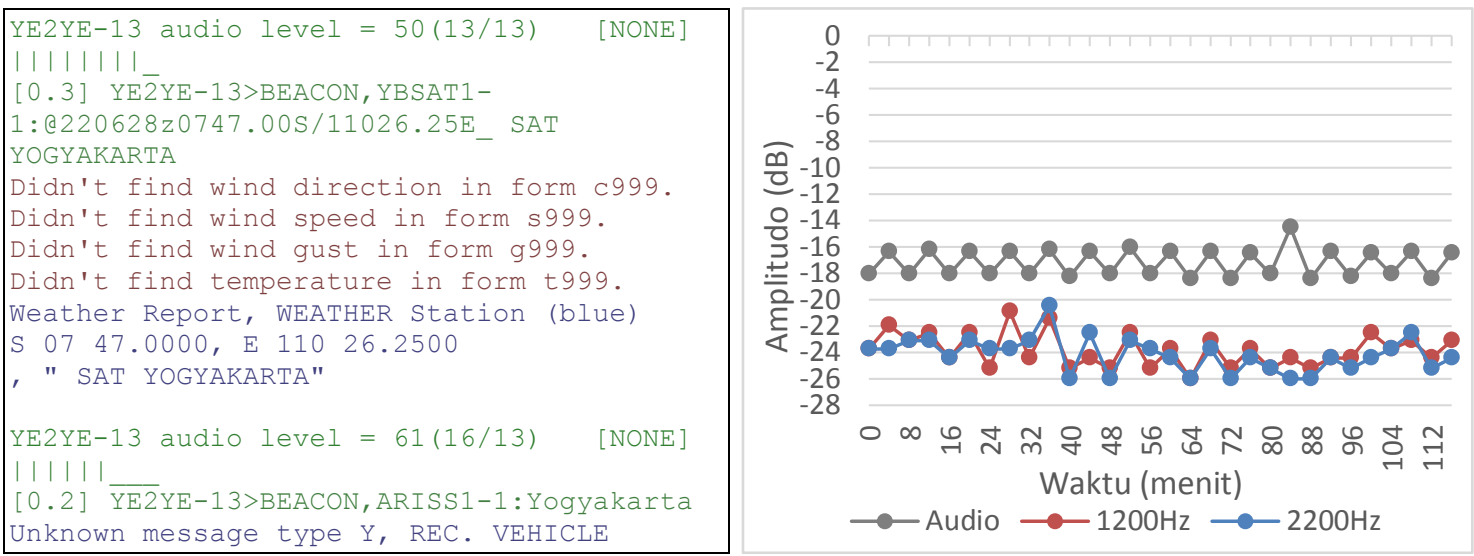

Gambar 15 Potongan paket yang diterima dari YE2YE-13 (kiri) dan grafik amplitudo (kanan)

Terdapat paket error yang ditunjukkan oleh lonjakan pada grafik dengan nilai amplitudo audio -14,54 dB, amplitudo frekuensi $1.200 \mathrm{~Hz}$ dan $2.200 \mathrm{~Hz}$ masing-masing adalah 24,44 dB dan -26,02 dB. Amplitudo pada frekuensi $1.200 \mathrm{~Hz}$ dan $2.200 \mathrm{~Hz}$ terlihat tidak stabil yang dapat disebabkan karena pengaturan pemancar atau dapat pula karena gangguan di luar lingkungan. Hasil rata-rata dari amplitudo audio adalah $-17,19 \mathrm{~dB}$, amplitudo pada frekuensi 1.200 Hz sebesar $-23,83 \mathrm{~dB}$ dan amplitudo pada frekuensi $2.200 \mathrm{~Hz}$ sebesar $-24,18 \mathrm{~dB}$. Amplitudo audio menunjukkan nilai yang lebih besar dari pada amplitudo frekuensi $1.200 \mathrm{~Hz}$ dan $2.200 \mathrm{~Hz}$, meskipun tidak sekecil pada penerimaan dari digipeater ISS. Hal ini menunjukkan bahwa YE2YE-13 memiliki sinyal yang lebih kuat dari pada digipeater ISS dari lokasi stasiun bumi.

\subsubsection{Pengujian Paket dari Radio UHF/VHF}

Radio dan penerima diatur ke frekuensi 144,390 Mhz, paket yang dipancarkan berupa pesan. Pemancaran dilakukan menggunakan aplikasi APRSDroid pada smartphone yang dihubungkan ke radio UHF/VHF. Volume suara untuk APRSDroid diatur ke $100 \%$. Pemancaran dilakukan dengan jeda kurang lebih 10 detik, pada tempat yang sama dengan jarak kurang lebih 20 meter dari posisi penerima. 
Amplitudo audio yang diperoleh memiliki nilai rata-rata $-19,72 \mathrm{~dB}$, rata amplitudo pada frekuensi $1.200 \mathrm{~Hz}$ adalah $-20,36 \mathrm{~dB}$ dan pada frekuensi $2.200 \mathrm{~Hz}$ adalah $-20,90 \mathrm{~dB}$. Nilai amplitudo pada pengujian ini lebih besar dari pada pengujian penerimaan dari satelit ISS dan stasiun cuaca YE2YE-13, terutama perbedaannya yang signifikan terhadap perbandingan antara amplitudo audio dengan amplitudo frekuensi. Hal ini menunjukkan bahwa diperoleh sinyal yang lebih kuat. Nilai amplitudo audio yang hampir sama dengan amplitudo frekuensi menunjukkan tingkat derau yang kecil. Gambar 16 (kiri) menunjukkan potongan paket yang diterima dari radio UHF/VHF dengan callsign YC2WKC-7, sedangkan Gambar 16 (kanan) adalah grafik amplitudo.
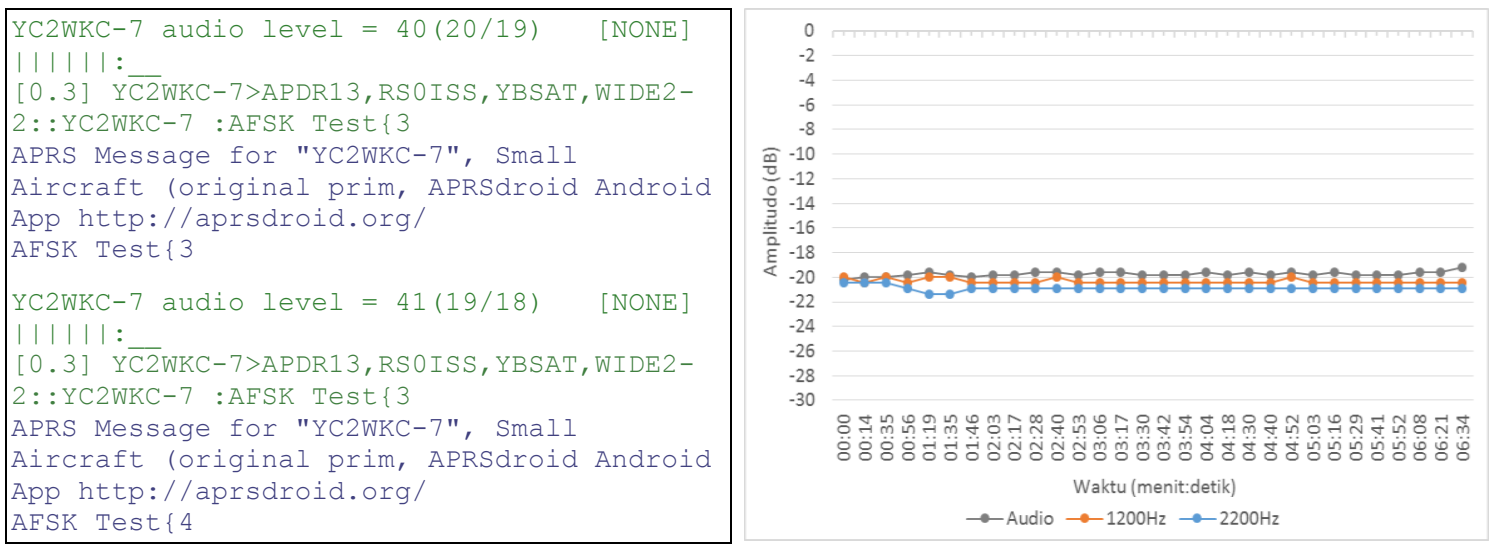

Gambar 16 Potongan paket yang diterima dari radio UHF/VHF (kiri) dan grafik amplitudo (kanan)

\section{KESIMPULAN}

Purwarupa penerima paket APRS berbasis Raspberry Pi 2 untuk stasiun bumi telah berhasil dibuat dan mampu menerima paket APRS dari digipeater ISS, stasiun cuaca YE2YE13, dan radio UHF/VHF. Penerima paket APRS dapat menerima paket dari digipeater ISS dengan jumlah 6 paket dari 10 paket yang dipancarkan. Paket APRS yang diterima dari digipeater ISS memiliki rata-rata amplitudo audio sebesar $-15,08 \mathrm{~dB}$, amplitudo pada frekuensi 1.200 Hz sebesar -24,95 dB dan pada $2.200 \mathrm{~Hz}$ sebesar $-25,61 \mathrm{~dB}$, nilai ini menunjukkan tingkat derau yang tinggi. Paket dari digipeater satelit LAPAN-A2 tidak dapat diperoleh, hal ini bisa disebabkan karena daya digipeater satelit yang kecil dan jarak yang lebih jauh dibanding satelit ISS. Sudut elevasi satelit, besar daya pada digipeater satelit dan jarak satelit atau pemancar berpengaruh pada transmisi sinyal.

\section{SARAN}

Beberapa saran terkait dengan apa yang telah dilakukan pada penelitian ini dan bisa menjadi pengembangan topik penelitian ini antara lain, antena dengan faktor penguatan yang lebih besar perlu digunakan agar kerugian sinyal akibat jarak dapat dikurangi, demikian juga antena pada radio untuk pemancaran paket ke satelit. Posisi penerima perlu ditempatkan di lokasi yang memiliki gangguan lingkungan lebih sedikit, sehingga sistem dapat menerima sinyal dengan lebih baik. Perangkat SDR dengan kemampuan pancar-terima perlu digunakan agar dapat melakukan pengiriman dan penerimaan paket APRS. 


\section{DAFTAR PUSTAKA}

[1] M.B. Sruthi, M. Abirami, A. Manikkoth, R. Gandhiraj, and K.P. Soman, "Low cost digital transceiver design for Software Defined Radio using RTL-SDR". in 2013 International Multi-Conference on Automation, Computing, Communication, Control and Compressed Sensing Proceeding, 2013 [Online], pp.852-855. Available: https://ieeexplore.ieee.org/document/6526525

[2] R. Danymol, T. Ajitha, and R. Gandiraj, "Real-Time Communication System Design using RTL-SDR and Raspberry". in 2013 International Conference on Advanced Computing and Communication Systems (ICACCS -2013) Proceeding, 2013 [Online], pp.1-5. Available: https://ieeexplore.ieee.org/document/6938691

[3] K. Hajdarevic and S. Konjicija, 2015, "A Low Energy Computer Infrastructure for Radio VOIP Supported Communication and SDR APRS in Education and Disaster Relief Situations", in 38th International Convention on Information and Communication Technology, Electronics and Microelectronics (MIPRO), 2015 [Online], pp.556-561. Available: https://ieeexplore.ieee.org/document/7160334

[4] S. Miller, "1200 Baud Packet Radio Details" N1VG's Projects and Stuff, http://n1vg.net/packet/index.php [Accessed March 14, 2019].

[5] Electron18, "Interface specification for transmission of binary data by frequency manipulation FSK, 2010 [Online]. Available: http://www.softelectro.ru/bell202_en.html [Accessed March 14, 2019].

[6] APRSdroid, "APRSdroid - APRS for Android", 2017 [Online]. Available: https://aprsdroid.org/ [Accessed March 14, 2019].

[7] Laidukas, "Mods and performance of R820T2 based RTL SDR receiver" RTL-SDR.com, https://www.rtl-sdr.com/mods-performance-r820t2-rtl-sdr/ [Accessed March 14, 2019].

[8] FTDI, "Application Note AN_146 USB Hardware Design Guidelines for FTDI ICs. Technology", [Online]. $\quad 2014 \quad$ Available: https://www.ftdichip.com/Documents/AppNotes/AN_146_USB_Hardware_Design_Guidel ines_for_FTDI_ICs.pdf

[9] Mobatek, "MobaXterm - Enhanced terminal for Windows with X11 server, tabbed SSH client, network tools and much more", 2018 [Online]. Available: http://mobaxterm.mobatek.net [Accessed March 14, 2019].

[10] K. Keen, "RTL-SDR experimental branch", 2015 [Online]. Available: https://github.com/keenerd/rtl-sdr [Accessed March 14, 2019].

[11] J. Langner, "Dire Wolf User Guide", 2016 [Online]. Available: https://github.com/wb2osz/direwolf/blob/master/doc/User-Guide.pdf

[12]M. Wakita, "All Satellites Frequency List Update", 2019 [Online]. Available: http://www.ne.jp/asahi/hamradio/je9pel/satslist.doc [Accessed March 13, 2019]. 